THERMAL AND ABLATIVE LAG INDUCED BY A PERIODIC HEAT INPUT

by

R. J. NICHOLS and M. SICHEL

The University of Michigan

Ann Arbor, Michigan

AlAA Paper

No. 67-336

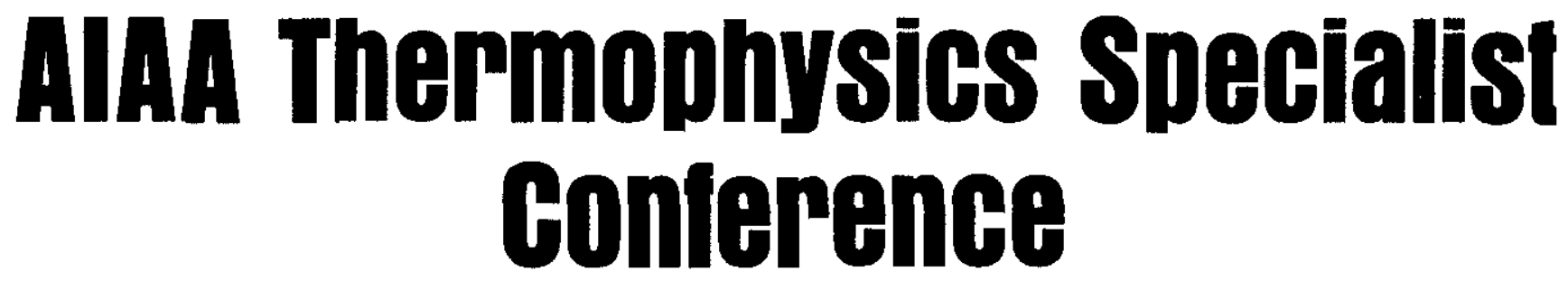

NEW ORLEANS, LOUISIANA/APRIL 17.20, 1967 
THERMAL AND MLLATIVE LAG

INDUCED BY A PERIOIIC HEAT INPUT

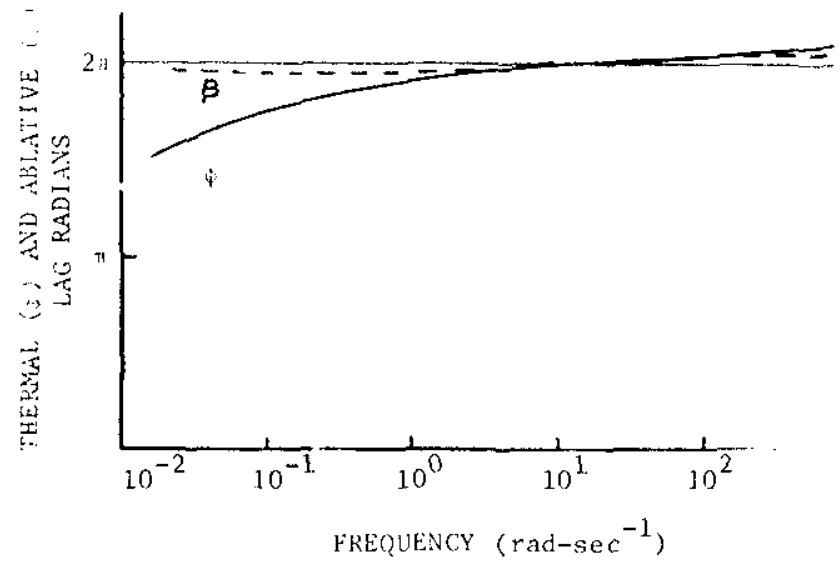

Figure 2. Thermal and Ablative Lag as a Function of Frequency for an Oscillating Flat Teflon Plate-.. No Mass Blockage

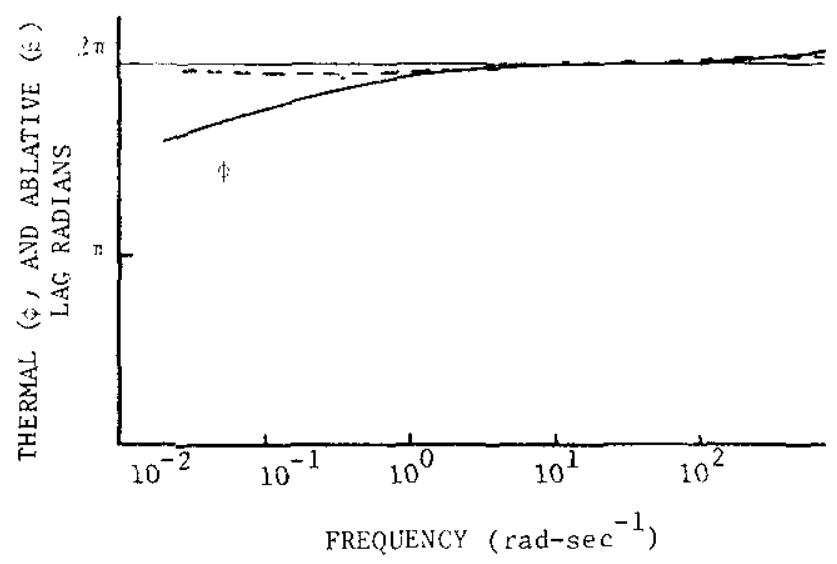

Figure 3. Thermal and Ablative Lag as a Function of Frequency for an Oscillating Flat Plate of Quartz - No Mass Blockage

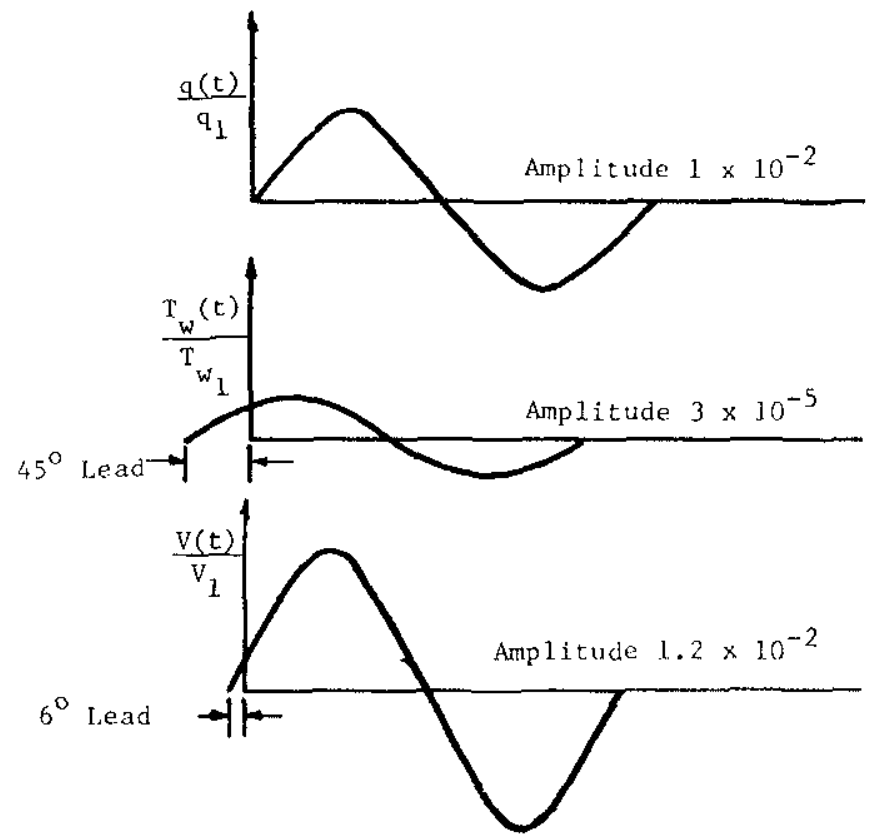

Figure 6. Pictorial Representations of Amplitude and Lag of the Thermal and Ablative Oscillations Relative to the Forcing Heat Input Oscillation at $\omega=10^{-1}$ Radians per Second

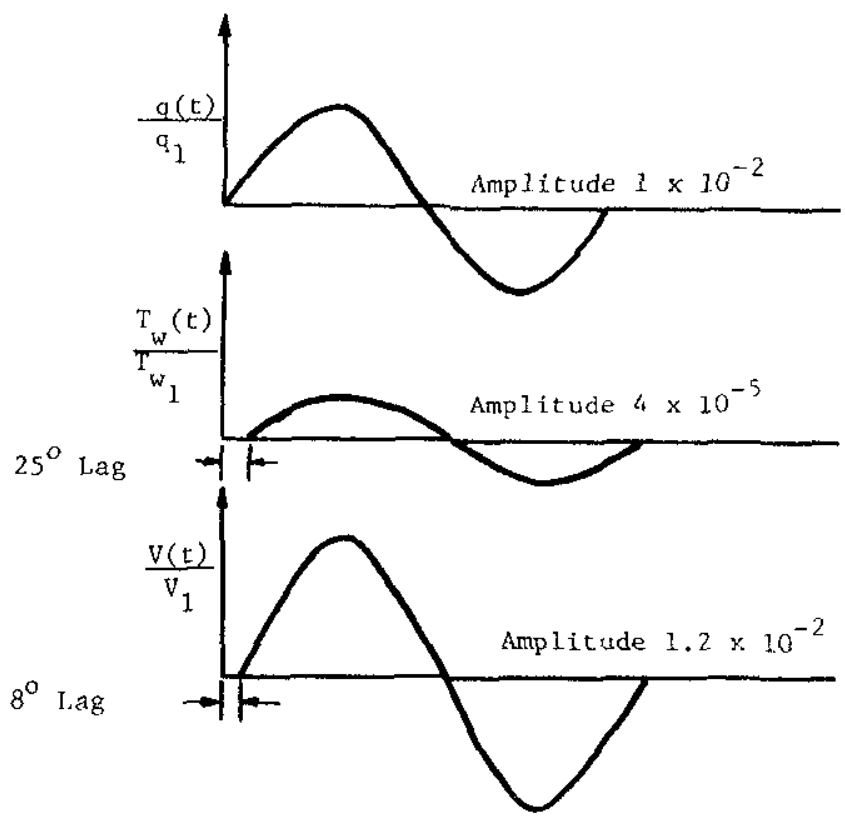

Figure 7. Pictorial Representation of Amplitude and Lag of the Thermal and Ablative Oscillations Relative to the Forcing Heat Input Oscillation at $\omega=10^{3}$ Radians per Second 


\title{
THERMAL AND ABLATIVE LAG INDUCED BY A PERIODIC HEAT INPUT*
}

\author{
R. J. Nichols and M. Sichel \\ The University of Michigan \\ Ann Arbor, Michigan
}

\section{Abstract}

The thermal and ablative lag induced by a periodic heat input to an oscillating flat plate in a high velocity flow is investigated. A perturbation approach is employed reducing the energy equation for a semi-infinite slab with a moving boundary to a second order linear nonhomogeneous differential equation with linear boundary conditions. The analytic solution is obtained for a pure vaporizer including effects of surface recession and mass blockage. The importance of this solution is the revelation of a crossover from a dynamically stabilizing to a destabilizing condition (or vice versa, dependent upon the distribution of ablative surface relative to the plate center of gravity as the frequency of oscillation increases. The effect of material on this crossover frequency is also shown. In the limit as frequency tends toward infinity, ablation velocity negligible compared to propagation velocity, the temperature lag approaches $\pi / 4$ and the ablative lag approaches zero (the result for zero ablation velocity as derived by Carslaw and Jaeger, Conduction of Heat in Solids).

\section{List of Symbols}

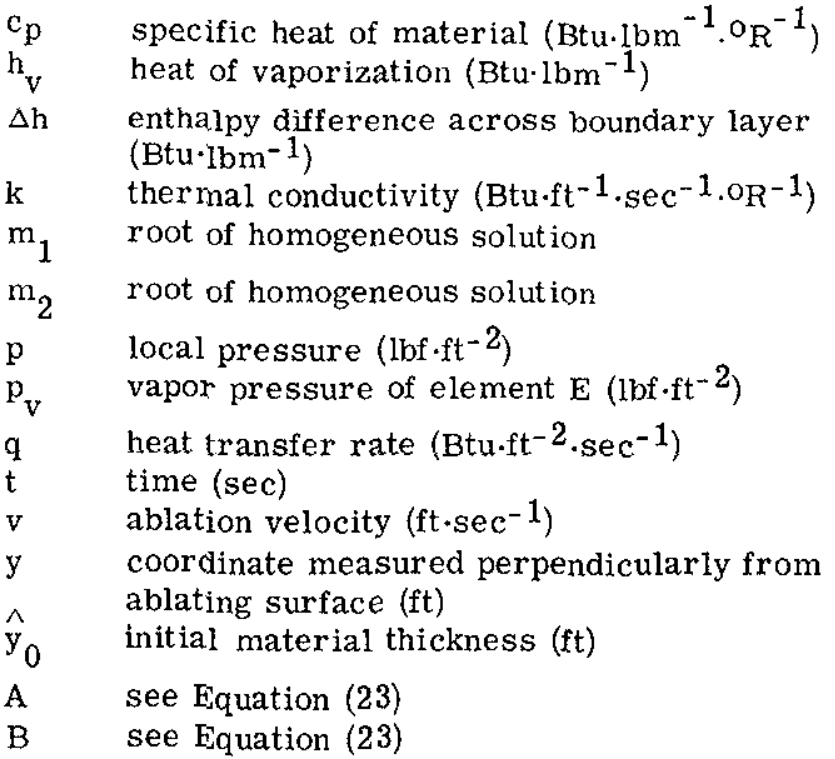

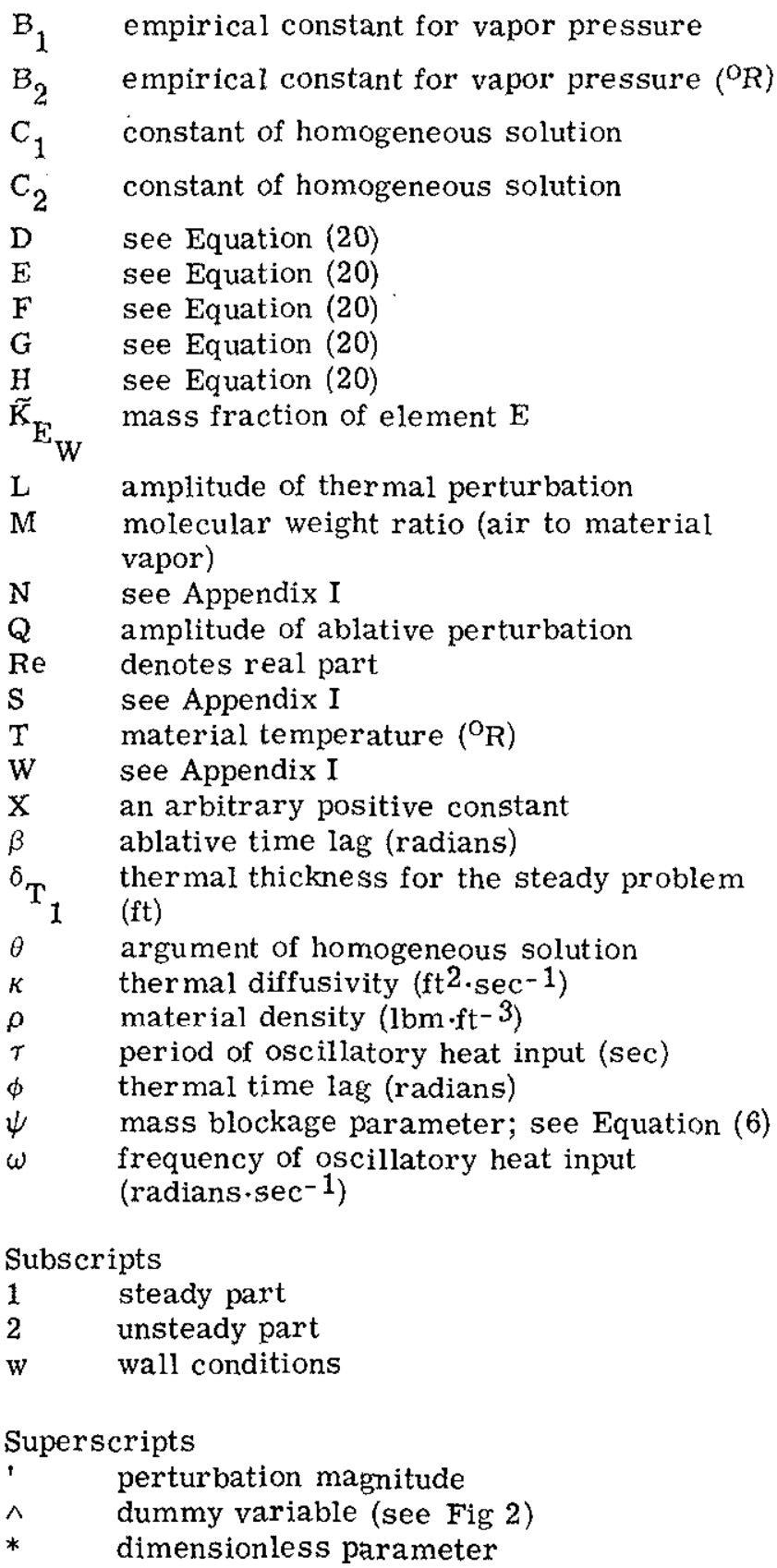

\footnotetext{
* This work was supported by the Advanced Research Projects Agency, under Contract SD-91 (ARPA Order 236) as a part of Project DEFENDER.
} 


\section{Introduction}

An oscillating plate in a high-velocity flow and its resultant material temperature and ablation rate oscillations are investigated as they relate to the dynamic stability of the plate. This is accomplished through an investigation of the somewhat simplified case of a periodic heat input to a stationary flat plate in a high-velocity flow. A perturbation approach is employed, reducing the energy equation for a semi-infinite slab with a moving boundary to a second-order linear nonhomogeneous differential equation with linear boundary conditions. An analytic solution for the thermal and ablative oscillations is obtained for a pure vaporizer; it includes effects of surface recession and mass blockage. The effects of frequency of oscillation and material properties on the ablative lag and dynamic stability of the plate are discussed.

\section{Mathematical Formulation of Problem}

The problem is thus to determine the thermal and ablative behavior of a semi-infinite slab of a pure vaporizer exposed to a periodic heat input,

$$
\begin{aligned}
q(t) & =q_{1}+q_{2}(t) \\
& =q_{1}+q^{\prime} \cos \omega t \\
& =q_{1}+q^{\prime} \operatorname{Re}\left(e^{i \omega t}\right)
\end{aligned}
$$

( $q^{\prime} \ll q_{1}$ and real where Re denotes real part). The time lag through the boundary layer, as has, for example, been discussed by Lighthill ${ }^{(1)}$ and Rott, $(2)$ is not considered in this simplified case. Further, the heat input to the plate is assumed quasi-uniform; i.e., transverse heat conduction is neglected. Flow properties at the external edge of the boundary layer are treated as constant, although variations of these properties with time can be handled by the method outlined here. Finally, the material is a pure vaporizer, introducing no additional complications due to a liquid boundary layer.

Figure 1 indicates the heat input $q(t)$ and the surface receding with time. The governing equation is the energy equation in the solid (Fourier's heat conduction equation),

$$
\frac{\partial T}{\partial \hat{t}}=\kappa \frac{\partial^{2} T}{\partial \hat{y}^{2}}
$$

where $\mathrm{T}$ is temperature and $\kappa$ is thermal diffusivity. Transforming to a coordinate system fixed with respect to the ablating surface,

$$
\begin{aligned}
& t=\hat{t} \\
& y=\left(\hat{y}-\hat{y}_{0}\right)+\int_{0}^{t} v(t) d t
\end{aligned}
$$

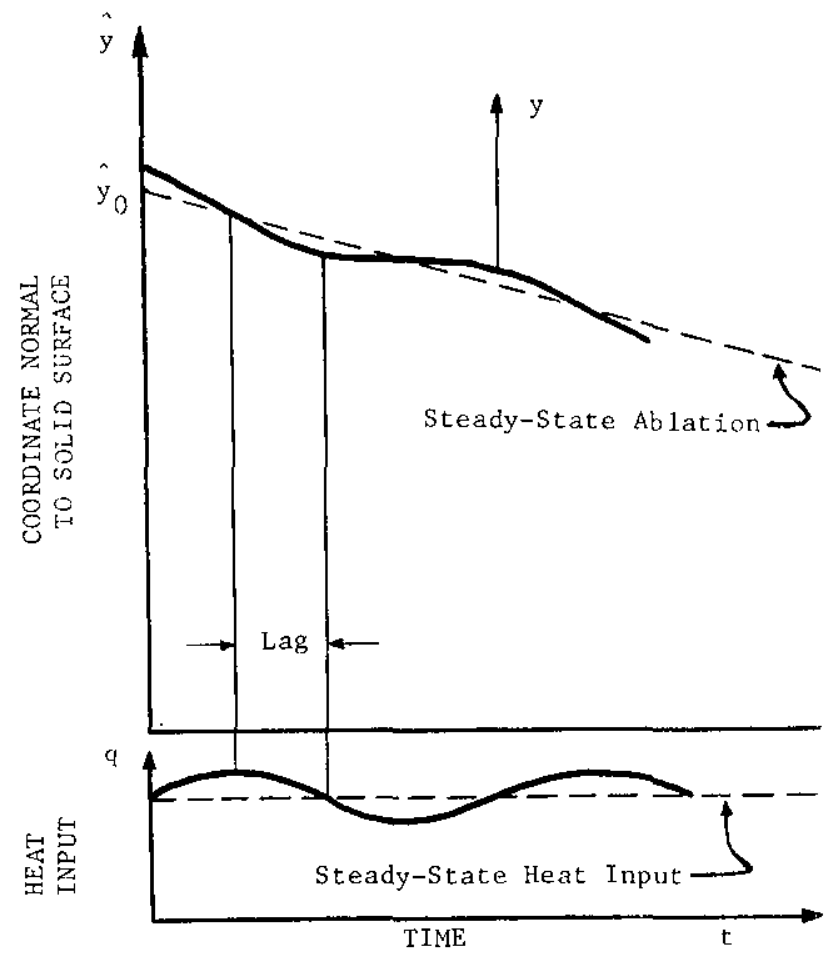

Figure 1. Semi-Infinite Slab with Periodic Heat Input and Ablation

where $\mathrm{v}$ is the ablation velocity in the positive $\mathrm{y}$ direction. Then since

$$
\frac{\partial}{\partial y}=\frac{\partial}{\partial \hat{y}}
$$

and

$$
\frac{\partial}{\partial \hat{t}}=\frac{\partial}{\partial t}+v(t) \frac{\partial}{\partial y}
$$

the energy conduction equation in the moving y coordinate system becomes

$$
\frac{\partial T}{\partial t}+v(t) \frac{\partial T}{\partial y}=\kappa \frac{\partial^{2} T}{\partial y^{2}}
$$

The boundary conditions follow.

1. Temperature bounded as $y \rightarrow-\infty$

$$
\mathrm{T}<\mathrm{X} \text { for } \mathrm{y}<0
$$

where $\mathrm{X}$ is some positive constant. 
2. The heat transfer at the wall, neglecting radiative emission, is the oscillatory heat input $q(t)$ reduced by the effect of vaporization or mass blockage in the boundary layer and the latent heat of vaporization.

$\left.\mathrm{k} \frac{\partial \mathrm{T}}{\partial \mathrm{y}}\right|_{\mathrm{y}=0} \equiv \mathrm{q}_{\mathrm{w}}(\mathrm{t})$

$$
\begin{gathered}
=\mathrm{q}(\mathrm{t})-\underbrace{0.68 \mathrm{M}^{0.26} \Delta \mathrm{h} \rho \mathrm{v}(\mathrm{t})}_{\text {Mass Blockage }}-\underbrace{\rho \mathrm{v}(\mathrm{t}) \mathrm{h}_{\mathrm{v}}}_{\begin{array}{c}
\text { Heat of } \\
\text { Vaporization }
\end{array}} \\
=\psi \mathrm{q}(\mathrm{t})-\rho \mathrm{v}(\mathrm{t}) \mathrm{h}_{\mathrm{v}}
\end{gathered}
$$

where $\psi$ is the mass blockage parameter given by the empirical relation

$$
\psi=1-0.68 \mathrm{M}^{0.26}\left(\frac{\Delta \mathrm{h}(\rho \mathrm{v}) \mathrm{W}}{\mathrm{q}(\mathrm{t})}\right)
$$

$\Delta \mathrm{h}$ is the enthalpy difference across the boundary layer

$\mathrm{M}$ is the molecular weight ratio (air to material vapor)

$\mathrm{k}$ is the thermal conductivity

$\rho$ is material density

$v(t)$ is the ablation velocity

$\mathrm{h}$ is the heat of vaporization

subscript $w$ denotes wall conditions

\section{Solution}

In order to determine what the nondimensionalized energy equation reveals about a solution, write equation (4) in nondimensionalized form. Introducing the dimensionless parameters denoted by ${ }^{*}$,

$$
t^{*}=\frac{t}{\tau}=\frac{t \omega}{2 \pi}
$$

where $\tau$ is the period of the oscillatory heat input,

$$
T^{*}=\frac{T}{T_{w_{1}} \exp \left(\frac{v_{1} y}{\kappa}\right)}
$$

where $\mathrm{T}_{\mathrm{w}_{1}} \exp \left(\mathrm{v}_{1} \mathrm{y} / \kappa\right)$ is the steady-state temperature. For $q^{\prime} \ll q_{1}$ it will be subsequently shown that $\mathrm{T}^{\prime} \ll \mathrm{T}_{1}, \mathrm{~T} \simeq \mathrm{T}_{\mathrm{w}_{1}} \exp \left(\mathrm{v}_{1} \mathrm{y} / \kappa\right)$, and $\mathrm{T}^{*}$ is of order one.

$$
\mathrm{y}^{*}=\frac{\mathrm{y}}{\delta_{\mathrm{T}}}=\frac{\mathrm{yv}_{1}}{\kappa}
$$

where $\delta_{T_{1}}$ is the thermal thickness for the steadystate problem, i.e., the distance y required for the temperature to decrease by $1 / \mathrm{e}$.

$$
v^{*}=\frac{v(t)}{v_{1}}
$$

where $v_{1}$ is the steady-state ablation velocity. For $q^{\prime} \ll q_{1}$, it will be shown that $v^{\prime} \ll v_{1}, v(t) \simeq v_{1}$, and $v^{*}$ is of order one.

Employing these dimensionless parameters, the energy equation (4) may be written

$\left.\frac{1}{2 \pi} \frac{\partial \mathrm{T}^{*}}{\partial \mathrm{t}^{*}}+\left(\frac{\mathrm{v}_{1}}{(\omega \kappa)^{1 / 2}}\right)^{2} \mathrm{v}^{*} \frac{\partial \mathrm{T}^{*}}{\partial \mathrm{y}^{*}}=\left(\frac{\mathrm{v}_{1}}{(\omega \kappa)}\right)^{1 / 2}\right)^{2} \frac{\partial^{2} \mathrm{~T}^{*}}{\partial \mathrm{y}^{*}}$

Equation (7) now indicates that the problem may be considered quasi-steady if

$$
\frac{\mathrm{v}_{1}}{\omega \kappa}>>1
$$

since then the unsteady term is small compared to the steady-state terms, assuming of course that the dimensionless quantities are of order one. This corresponds to $\omega \ll 1$ cps for typical materials.

To determine the actual solution, the ablation velocity and surface temperature are written in terms of their steady and unsteady components:

$$
\begin{aligned}
\mathrm{v}(\mathrm{t}) & =\mathrm{v}_{1}+\mathrm{v}_{2}(\mathrm{t}) \\
\mathrm{T}(\mathrm{y}, \mathrm{t}) & =\mathrm{T}_{1}(\mathrm{y})+\mathrm{T}_{2}(\mathrm{y}, \mathrm{t}) \\
& =\mathrm{T}_{1}(\mathrm{y})+\operatorname{Re}\left[\mathrm{T}^{\prime}(\mathrm{y}) \mathrm{e}^{\mathrm{i} \omega \mathrm{t}}\right]
\end{aligned}
$$

where $T^{\prime}(y)$ is the complex amplitude of $T_{2}(y, t)$. Since the governing equations will be linearized, $T_{2}(y, t)$ will have the same frequency as $q(t)$ but will in general have a time lag $\phi$. For the perturbation $\mathrm{q}^{1} \ll \mathrm{q}_{1}$, it is assumed that the ablation velocity depends on $q$ and $T$ as in the steady case derived by Lees $^{(4)}$; that is,

$$
(\rho v)_{w}=\frac{\psi q(t)}{\Delta h}\left(\frac{\widetilde{K}_{E_{W}}}{1-\widetilde{K}_{E_{W}}}\right)
$$

where for no chemical reaction, the mass fraction of element $\mathrm{E}$ is

$$
\tilde{\mathrm{K}}_{\mathrm{E}_{\mathrm{W}}}=\left[1+\mathrm{M}\left(\frac{\mathrm{p}}{\mathrm{p}_{\mathrm{v}}}-1\right)\right]^{-1}
$$


or

$$
\frac{1-\tilde{\mathrm{K}}_{\mathrm{E}_{\mathrm{W}}}}{\tilde{\mathrm{K}}_{\mathrm{E}_{\mathrm{w}}}}=\mathrm{M}\left(\frac{\mathrm{p}}{\mathrm{p}_{\mathrm{v}}}-1\right)
$$

where $\mathrm{p}$ is local pressure

$p_{y}$ is vapor pressure of element $E$

III.1. Solution with No Mass Blockage

Although no great simplification arises by assuming no mass blockage $(\psi=1)$, the relations become more tractable. From (10) and (11), the ablation velocity

$$
\mathrm{v}(\mathrm{t})=\frac{\mathrm{q}(\mathrm{t})}{\rho \Delta \mathrm{hM}\left(\frac{\mathrm{p}}{\mathrm{p}_{\mathrm{v}}}-1\right)}
$$

is a function of $q(t)$ and wall temperature, the latter through $\Delta \mathrm{h}$ and $\mathrm{p}_{\mathrm{V}}(\Delta \mathrm{h}$ dependence weak). The vapor pressure $p_{y}$ of the ablating material is a function of both material temperature and local pressure. Neglecting the effect of pressure $p$, an empirical expression for the vapor pressure $p_{v}$ is

$$
\begin{aligned}
p_{v} & =\exp \left[B_{1}\left(1-B_{2} T_{w}^{-1}\right)\right] \\
& \cong p_{v_{1}}\left(1+\frac{B_{1} B_{2}}{T_{w_{1}}} \frac{T_{w_{2}}}{T_{1}}\right)
\end{aligned}
$$

where the following assumption has been made

$$
\frac{\mathrm{B}_{1} \mathrm{~B}_{2}}{\mathrm{~T}_{\mathrm{w}_{1}}} \frac{\mathrm{T}_{\mathrm{w}_{2}}}{\mathrm{~T}_{\mathrm{w}_{1}}} \ll 1
$$

Then from (12) and (13), ablation velocity may be written

$$
\begin{aligned}
& v(t)=\frac{q(t)\left[1+\frac{B_{1} B_{2}}{T_{w_{1}}\left(p-p_{v_{1}}\right)} \frac{T_{w_{1}}(t)}{T_{w_{1}}}\right]}{\rho \Delta h M\left(\frac{p}{p_{v_{1}}}-1\right)} \\
& =v_{1}+v_{1} \operatorname{Re}\left\{\left[\frac{q^{\prime}}{q_{1}}+\frac{B_{1} B_{2}}{T_{w_{1}}} \frac{p}{\left(p-p_{v_{1}}\right)^{T} w_{1}}\right] e^{T^{\prime}}\right\}
\end{aligned}
$$

where the second-order term has been dropped. Relations (4), (5), (6), and (14) set the problem.

At this juncture, the earlier assumptions that

$$
\mathrm{T}_{2} \ll \mathrm{T}_{1}
$$

and

$$
\mathrm{v}_{2} \ll \mathrm{v}_{1}
$$

for

$$
\mathrm{q}_{2} \ll \mathrm{q}_{1}
$$

may be verified. Equation (6) restricts ablation velocity perturbation to a magnitude comparable to that of the heat input. Further, acknowledging that temperature perturbations at depth y are less or equal to surface temperature perturbations,

$$
\begin{aligned}
T_{2}(y, t) & \leq T_{2}(0, t) \\
& \leq T_{w_{2}}(t)
\end{aligned}
$$

an examination of equation (14) reveals that ablation velocity perturbations are directly proportional to

$$
\frac{\mathrm{q}_{2}}{\mathrm{q}_{1}}+\frac{\mathrm{B}_{1} \mathrm{~B}_{2}}{\mathrm{~T}_{\mathrm{w}_{1}}} \frac{\mathrm{p}}{\left(\mathrm{p}-\mathrm{p}_{v_{1}}\right)} \frac{\mathrm{T}_{\mathrm{w}_{2}}(\mathrm{t})}{\mathrm{T}_{\mathrm{w}_{1}}}
$$

Since the vapor pressure constant $\left(\mathrm{B}_{1} \mathrm{~B}_{2} / \mathrm{T}_{\mathrm{w}_{1}}\right)$ $\left[\mathrm{p} /\left(\mathrm{p}-\mathrm{p}_{\mathrm{v}}\right)\right]$ is in general of order 10 , temperature perturbation must then be of order $10^{-1}$ or less than the order of the heat input.

The differential equation (4) may now be reduced to a second-order linear nonhomogeneous differential equation by substituting (9) and (14) and neglect-ing second-order terms:

$$
\begin{aligned}
i \omega T^{\prime} e^{i \omega t}+v_{1}\left[\frac{q^{\prime}}{q_{1}}+\frac{T^{\prime}}{T_{w_{1}}} \frac{B_{1} B_{2}}{T_{1}} \frac{p}{\left(p-p_{v}\right)}\right] e^{i \omega t} \frac{d T_{1}}{d y} \\
+v_{1} \frac{d T^{\prime}}{d y}+v_{1} \frac{d T_{1}}{d y}=k e^{i \omega t \frac{d^{2} T^{\prime}}{d y^{2}}+k \frac{d^{2} T_{1}}{d y^{2}}}
\end{aligned}
$$

Eliminating the steady-state part 


$$
\begin{aligned}
& i \omega T^{\prime}(y)\left.+v_{1}\left(\frac{q^{\prime}}{q_{1}}+\frac{B_{1} B_{2}}{T_{w_{1}}} \frac{p}{\left(p-p_{v_{1}}\right.}\right)^{T_{w_{1}}}\right) \frac{T^{\prime}}{d y} \\
&+v_{1} \frac{d T^{\prime}}{d y}=\kappa \frac{d^{2} T^{\prime}}{d y^{2}}
\end{aligned}
$$

For the vaporizing case, the steady-state temperature is identically $(3)$

$$
\mathrm{T}_{1}=\mathrm{T}_{\mathrm{w}_{1}} \exp \frac{\mathrm{v}_{1} \mathrm{y}}{\kappa}
$$

or

$$
\frac{\mathrm{dT}_{1}}{\mathrm{dy}}=\frac{\mathrm{T}_{1} \mathrm{v}_{1}}{\kappa} \exp \frac{\mathrm{v}_{1} \mathrm{y}}{\kappa}
$$

and (15) becomes

$$
\begin{aligned}
& \frac{d^{2} T^{\prime}}{d y^{2}}-\frac{v_{1}}{\kappa} \frac{d T^{\prime}}{d y}-\frac{i \omega}{\kappa} T^{\prime} \\
& =\left(\frac{{ }^{v}}{\kappa}\right)^{2}\left[\frac{q^{\prime}}{q_{1}}+\frac{B_{1} B_{2}}{T_{w_{1}}\left(p-p_{v_{1}}\right)} \frac{\mathrm{p}^{\prime}}{T_{w_{1}}}\right] T_{w_{1}} \exp \frac{v_{1} y}{\kappa}
\end{aligned}
$$

While $q^{\prime}$ is given, $T^{\prime}{ }_{w}$ is unknown and behaves some what like an eigenvalue of the problem. The roots of the homogeneous equation are

$$
\mathrm{m}_{1}, \mathrm{~m}_{2}=\frac{\mathrm{v}_{1}}{2 \kappa} \pm \frac{\mathrm{v}_{1}}{2 \kappa}\left[1+\left(\frac{4 \omega \kappa}{\mathrm{v}_{1}^{2}}\right)^{2}\right]^{1 / 4} \exp \frac{\mathrm{i} \theta}{2}
$$

where

$$
0=\tan ^{-1}\left(\frac{4 \omega k}{v_{1}^{2}}\right)
$$

The homogeneous solution for $\mathrm{T}^{\prime}$ for all $\omega$ is

$$
T^{\prime}=C_{1} e^{m_{1} y}+C_{2} e^{m_{2} y}
$$

Since

$$
\operatorname{Re}\left(m_{1}\right)>0 \text { always }
$$

and

$$
\operatorname{Re}\left(m_{2}\right)<0 \text { always }
$$

Therefore, $C_{2}=0$ for boundedness as $y \rightarrow-\infty$. The particular solution is

$$
\mathrm{T}^{\prime}=i \frac{\mathrm{v}_{1}^{2}}{\kappa \omega}\left[\frac{\mathrm{q}^{\prime}}{\mathrm{q}_{1}}+\frac{\mathrm{B}_{1} \mathrm{~B}_{2}}{\mathrm{~T}_{\mathrm{w}_{1}}} \frac{\mathrm{p}}{\left(p-\mathrm{p}_{\mathrm{v}_{1}}\right)} \frac{\mathrm{T}^{\prime} \mathrm{w}}{\mathrm{T}_{\mathrm{w}_{1}}}\right] \mathrm{T}_{\mathrm{w}_{1}} \exp \left(\frac{\mathrm{v}_{1} \mathrm{y}}{\kappa}\right)
$$

so that the general solution is

$$
\begin{aligned}
\mathrm{T}^{\prime} & =\mathrm{C}_{1} \mathrm{e}^{\mathrm{m}_{1} \mathrm{y}} \\
& +\mathrm{i} \frac{\mathrm{v}_{1}}{\kappa \omega}\left[\frac{2}{\mathrm{q}_{1}}+\frac{\mathrm{B}_{1} \mathrm{~B}_{2}}{\mathrm{~T}_{\mathrm{w}_{1}}} \frac{\mathrm{p}}{\left.\mathrm{p}-\mathrm{p}_{\mathrm{v}_{1}}\right)} \frac{\mathrm{T}^{\prime} \mathrm{w}}{\mathrm{T}_{\mathrm{w}}}\right] \mathrm{T}_{\mathrm{w}_{1}} \exp \left(\frac{\mathrm{v}_{1} \mathrm{y}}{\kappa}\right)
\end{aligned}
$$

or

$$
\begin{aligned}
\mathrm{T}^{\prime}= & \mathrm{C}_{1} \exp D y(\cos E y+i \sin E y) \\
& +i F \exp G y+i H T^{\prime}{ }_{w} \exp G y
\end{aligned}
$$

where

$$
\begin{aligned}
& \mathrm{D}=\frac{\mathrm{v}_{1}}{2 \kappa}\left\{1+\left[1+\left(\frac{4 \omega \kappa}{2}\right)^{2}\right]^{1 / 4} \cos \frac{\theta}{2}\right\} \\
& \mathrm{E}=\frac{\mathrm{v}_{1}}{2 \kappa}\left[1+\left(\frac{4 \omega \kappa}{\mathrm{v}_{1}}\right)^{2}\right]^{1 / 4} \sin \frac{\theta}{2} \\
& \mathrm{~F}=\frac{\mathrm{v}_{1}{ }^{2}}{\kappa \omega} \frac{\mathrm{q}^{\prime}}{\mathrm{q}_{1}} \mathrm{~T}_{\mathrm{w}_{1}} \\
& \mathrm{G}=\frac{\mathrm{v}_{1}}{\kappa} \\
& \mathrm{H}=\frac{\mathrm{v}_{1}}{\kappa \omega} \frac{\mathrm{B}_{1} \mathrm{~B}_{2}}{\mathrm{~T}_{\mathrm{w}_{1}}} \frac{\mathrm{p}}{\left.\mathrm{p}-\mathrm{p}_{\mathrm{v}_{1}}\right)}
\end{aligned}
$$

Setting $\mathrm{y}=0$ in (20) and solving for $\mathrm{T}^{\prime}(0)=\mathrm{T}^{\prime}{ }_{\mathrm{W}}$,

$$
\mathrm{T}_{\mathrm{w}}^{\prime}=\frac{\mathrm{C}_{1}+\mathrm{iF}+\mathrm{iC}_{1} \mathrm{H}-\mathrm{FH}}{1+\mathrm{H}^{2}}
$$

To determine the unknown constant $\mathrm{C}_{1}$, the remaining boundary condition, equation (6), for the heat transfer to the wall must be used. For $\psi=1$ 


$$
\left.k \frac{\partial T}{\partial y}\right|_{y=0}=q(t)-\rho v(t) h_{v}
$$

Using (14) and (1),

$$
\begin{aligned}
& \left.k \frac{\partial T}{\partial y}\right|_{y=0}=\left(q_{1}-\rho v_{1} h_{v}\right)+\frac{q^{\prime}}{q_{1}} e^{i \omega t}\left(q_{1}-\rho v_{1} h_{v}\right) \\
& -\frac{\mathrm{B}_{1} \mathrm{~B}_{2}}{\mathrm{~T}_{w_{1}}}\left(\mathrm{p}-\mathrm{p}_{\mathrm{v}_{1}}\right)\left(\rho \mathrm{h}_{\mathrm{v}} \mathrm{v}_{1}\right) \frac{\mathrm{T}^{\prime} \mathrm{T}_{\mathrm{w}_{1}}}{\mathrm{i}}
\end{aligned}
$$

Since (from Ref. 3) $q_{1}-\rho v_{1} h_{v}=\rho v_{1} c_{p} T_{w_{1}}$

$$
\begin{aligned}
& \left.\frac{\partial \mathrm{T}}{\partial \mathrm{y}}\right|_{\mathrm{y}=0}=\frac{\mathrm{v}_{1}}{\kappa} \mathrm{T}_{\mathrm{w}_{1}}+\frac{\mathrm{v}_{1}}{\kappa} \frac{\mathrm{q}^{\prime}}{\mathrm{q}_{1}} \mathrm{~T}_{\mathrm{w}_{1}} \mathrm{e}^{\mathrm{i} \omega \mathrm{t}} \\
& -\frac{v_{1} B_{1} B_{2}}{\kappa} \frac{p}{T_{w_{1}}}\left(p-p_{v_{1}}\right) \frac{h_{v}}{c_{p} T_{w}} T^{\prime}{ }^{\prime} e^{i \omega t}
\end{aligned}
$$

or

$$
\begin{aligned}
\left.\frac{\mathrm{dT}^{\prime}}{\mathrm{dy}}\right|_{\mathrm{y}=0}= & {\left[-\frac{\mathrm{v}_{1} \mathrm{~B}_{1} \mathrm{~B}_{2}}{\kappa} \frac{\mathrm{p}}{\mathrm{T}_{\mathrm{w}_{1}}} \frac{\mathrm{h}_{\mathrm{v}}}{\left(\mathrm{p}-\mathrm{p}_{\mathrm{v}_{1}}\right)} \frac{\mathrm{c}_{\mathrm{p}^{\mathrm{T}} \mathrm{w}_{1}}}{\mathrm{~T}^{\prime}} \mathrm{T}_{\mathrm{w}}^{\prime}\right.} \\
& +\frac{\mathrm{v}_{1}}{\kappa} \frac{\mathrm{q}_{1}^{\prime} \mathrm{T}_{\mathrm{w}_{1}}=\mathrm{AT}_{\mathrm{w}}^{\prime}+\mathrm{B}}{\mathrm{q}_{1}}
\end{aligned}
$$

where

$$
\begin{aligned}
& \mathrm{A}=-\frac{\mathrm{v}_{1}}{\kappa} \frac{\mathrm{B}_{1} \mathrm{~B}_{2}}{\mathrm{~T}_{\mathrm{w}_{1}}} \frac{\mathrm{h}_{\mathrm{v}}}{\mathrm{c}_{\mathrm{p}} \mathrm{T}_{\mathrm{w}_{1}}} \frac{\mathrm{p}}{\left.\mathrm{p}-\mathrm{p}_{\mathrm{v}_{1}}\right)} \\
& \mathrm{B}=\frac{\mathrm{v}_{1}}{\kappa} \frac{\mathrm{q}^{\prime}}{\mathrm{q}_{1}} \mathrm{~T}_{\mathrm{w}_{1}}
\end{aligned}
$$

Then, to solve for the complex constant $C_{1},(21)$ is substituted in (19) and (23), and the derivative of (19) evaluated at $\mathrm{y}=0$ is equated to (23). $\mathrm{C}_{1}$ is given in Appendix I. $\mathrm{T}^{\prime}{ }_{\mathrm{w}}$ may then be written

$$
\mathrm{T}^{\prime}{ }_{\mathrm{w}}=\frac{\mathrm{W}+\mathrm{iN}}{\mathrm{S}}+\frac{\mathrm{i} \mathrm{F}(1+\mathrm{iH})}{\left(1+\mathrm{H}^{2}\right)}
$$

where W, N, and S are defined in Appendix I. Taking the real part of $\left(\mathrm{T}^{\prime} \mathrm{e}^{i \omega \mathrm{t}}\right)$,

$$
\mathrm{T}_{\mathrm{w}}=\mathrm{T}_{\mathrm{w}_{1}}+\cos \omega \mathrm{t}\left(\frac{\mathrm{W}}{\mathrm{S}}-\frac{\mathrm{HN}}{\mathrm{S}}-\frac{\mathrm{HF}}{1+\mathrm{H}^{2}}\right)
$$

$$
+\sin \omega t\left(-\frac{N}{S}-F-\frac{H W}{S}+\frac{H^{2} F}{1+H^{2}}\right)
$$

To determine time lag of the thermal oscillation relative to that of the heat input, note that equation (25) can also be written in the form

$$
\begin{aligned}
\mathrm{T}_{\mathrm{w}} & =\mathrm{T}_{\mathrm{w}_{1}}+\mathrm{L} \cos (\omega \mathrm{t}-\phi) \\
& =\mathrm{T}_{\mathrm{w}_{1}}+\mathrm{L} \cos \omega \mathrm{t} \cos \phi+\mathrm{L} \sin \omega \mathrm{t} \sin \phi
\end{aligned}
$$

Thus,

$$
\begin{aligned}
L \sin \phi= & \frac{-\mathrm{N}-\mathrm{FS}-\mathrm{HW}+\frac{\mathrm{H}^{2} F S}{1+\mathrm{H}^{2}}}{\mathrm{~S}} \\
\mathrm{~L} \cos \phi & =\frac{W-H N-\frac{\mathrm{HFS}}{\left(1+\mathrm{H}^{2}\right)}}{\mathrm{S}}
\end{aligned}
$$

$$
\phi=\tan ^{-1}\left(\frac{-N-F S-H W+\frac{H^{2} F S}{1+H^{2}}}{W-H N-\frac{H F S}{1+H^{2}}}\right)
$$

The ablation rate is obtained by combining (14) and the periodic part of (25). From (14),

$$
\begin{aligned}
v(t)= & v_{1}+v_{1}\left[\frac{q^{\prime}}{q_{1}} \cos \omega t\right. \\
& \left.+\frac{B_{1} B_{2}}{T_{w_{1}}} \frac{p}{\left(p-p_{v_{1}}\right.}\right)^{\frac{1}{T_{w_{1}}}} \operatorname{Re}\left(T^{\prime}{ }_{w} e^{i \omega t}\right) \\
= & v_{1}+Q \cos \omega t \cos \beta+Q \sin \omega t \sin \beta
\end{aligned}
$$

$$
\begin{aligned}
& Q \cos \beta=\left[\frac{q^{\prime}}{q_{1}}+\frac{B_{1} B_{2}}{\bar{T}_{w_{1}}}\left(\frac{p}{p-p_{v_{1}}}\right)^{T_{w_{1}}} \cos \phi\right] v_{1} \\
& \mathrm{Q} \sin \beta=\left[\frac{\mathrm{B}_{1} \mathrm{~B}_{2}}{\mathrm{~T}_{\mathrm{w}_{1}}}\left(\frac{\mathrm{p}}{\left.\mathrm{p}-\mathrm{p}_{\mathrm{v}_{1}}\right)} \frac{\mathrm{L}}{\mathrm{T}_{\mathrm{w}}} \sin \phi\right] \mathrm{v}_{1}\right.
\end{aligned}
$$

One must evaluate the individual constants for specific materials in order to further define the thermal and ablative lags. 
III.2. Solution with Mass Blockage

The velocity function must be changed to include mass blockage, as must the heat-transfer boundary condition at the surface. First (10) and (7) are solved, yielding

$$
\begin{aligned}
& \mathrm{v}(\mathrm{t})=-\frac{\mathrm{q}(\mathrm{t})}{\rho \Delta \mathrm{h} 0.68 \mathrm{M}^{0.26}\left[1+\frac{\mathrm{M}^{0.74}}{0.68}\left(\frac{\mathrm{p}}{\mathrm{p}_{\mathrm{v}}}-1\right)\right]} \\
& \psi \mathrm{q}(\mathrm{t})=\mathrm{q}(\mathrm{t})\left\{1-\left[1+\frac{\mathrm{M}^{0.74}}{0.68}\left(\frac{\mathrm{p}}{\mathrm{p}_{\mathrm{v}}}-1\right)\right]\right.
\end{aligned}
$$

The only difference between this and the previous treatment $(\psi=1)$ is that a more complicated development is required to determine the effect of temperature on vapor pressure and subsequently $\mathrm{v}(\mathrm{t})$ and $\psi(\mathrm{t})$. Substituting for vapor pressure $\mathrm{p}_{\mathrm{v}}$ from equation (13)

$$
\begin{aligned}
& \mathrm{v}(\mathrm{t})=\mathrm{v}_{1} \\
& +\mathrm{v}_{1} \operatorname{Re}\left\{\left[\frac{\mathrm{q}^{\prime}}{\mathrm{q}_{1}}+\frac{\rho \mathrm{v}_{1} \Delta \mathrm{h} \mathrm{M}}{\mathrm{q}_{1}} \frac{\mathrm{p}}{\mathrm{p}_{v_{1}}} \frac{\mathrm{B}_{1} \mathrm{~B}_{2}}{\mathrm{~T}_{1}} \frac{\mathrm{T}^{\prime}}{\mathrm{T}_{w_{1}}}\right] \mathrm{e}^{\mathrm{i} \omega t}\right\}
\end{aligned}
$$

The differential equation (4) is again reduced to a second-order linear nonhomogeneous differential equation by substituting (9) and (32) and neglecting second-order terms:

$$
\begin{aligned}
& \frac{d^{2} T^{\prime}}{d y^{2}}-\frac{v_{1}}{\kappa} \frac{d T^{\prime}}{d y}-\frac{i \omega T^{\prime}}{\kappa}=\left(\frac{v_{1}}{k}\right)^{2}\left[\frac{q^{\prime}}{q_{1}}\right. \\
& +\frac{\rho v_{1} \Delta h M}{q_{1}} \frac{p}{p_{v_{1}}} \frac{B_{1} B_{2}}{T_{w_{1}}} \frac{T^{\prime} T_{w_{1}}}{T_{1}} T_{w_{1}} \exp \frac{v_{1} y}{k}
\end{aligned}
$$

The boundary condition (6) becomes

$$
\begin{aligned}
q_{w}(t)= & \psi_{q}(t)-\rho v(t) h_{v} \\
= & \rho v_{1} c_{p} T_{w_{1}}\left(1+\frac{q^{\prime}}{q_{1}} \operatorname{Re} e^{i \omega t}\right) \\
& -\frac{\left(\rho v_{1}\right)^{2} \Delta h M}{q_{1}} \frac{p}{p_{v_{1}}}\left(0.68 \Delta h M^{0.26}+h_{v}\right) \\
& \frac{B_{1} B_{2}}{T_{w_{1}}} \operatorname{Re}\left(\frac{T_{w}^{\prime}}{T_{w}} e^{i \omega t}\right)
\end{aligned}
$$

Note that equations (20), (21), and (24) through (29) for material temperature are still valid, $A$ and $H$ having changed.

$$
\begin{aligned}
& A=\left[\frac{v_{1}}{k} w_{w_{1}}-\frac{q_{1}}{\rho c_{p} k}\right]\left[\frac{\rho v_{1} \Delta h M}{q_{1} T_{w_{1}}} \frac{B_{1} B_{2}}{T_{w_{1}}} \frac{p}{p_{v_{1}}}\right] \\
& \mathrm{H}=\frac{\mathrm{v}_{1}^{2}}{\kappa \omega} \frac{\rho \mathrm{v}_{1} \Delta \mathrm{h} M}{\mathrm{q}_{1}} \frac{\mathrm{p}}{\mathrm{p}_{\mathrm{v}_{1}}} \frac{\mathrm{B}_{1} \mathrm{~B}_{2}}{\mathrm{~T}_{\mathrm{w}_{1}}}
\end{aligned}
$$

The ablation velocity thus is obtained by combining (32) and the periodic part of (25)

$$
\begin{aligned}
& v(t)=v_{1}+v_{1}\left[\frac{q^{\prime}}{q_{1}} \cos \omega t\right. \\
& \left.+\frac{\rho v_{1} \Delta h M}{q_{1}} \frac{p}{p_{v_{1}}} \frac{B_{1} B_{2}}{T_{w_{1}}} \frac{1}{T_{w_{1}}} \operatorname{Re}\left(T_{w}^{\prime} e^{i \omega t}\right)\right] \\
& =v_{1}+v_{1}(Q \cos \omega t \cos \beta+Q \sin \omega t \sin \beta) \\
& \mathrm{Q} \cos \beta=\frac{\mathrm{q}^{\prime}}{\mathrm{q}_{1}}+\frac{\rho \mathrm{v}_{1} \Delta \mathrm{h} \mathrm{M}}{\mathrm{q}_{1}} \frac{\mathrm{p}_{1}}{\mathrm{p}_{\mathrm{v}_{1}} \mathrm{~B}_{\mathrm{w}_{1}} \mathrm{~B}_{2}} \frac{1}{\mathrm{~T}_{\mathrm{w}_{1}}} \mathrm{~L} \cos \phi \\
& \mathrm{Q} \sin \beta=\frac{\rho \mathrm{v}_{1} \Delta \mathrm{h} M}{\mathrm{q}_{1}} \frac{\mathrm{p}}{\mathrm{p}_{\mathrm{v}_{1}}} \frac{\mathrm{B}_{1} \mathrm{~B}_{2}}{\mathrm{~T}_{\mathrm{w}_{1}}} \frac{1}{\mathrm{~T}_{\mathrm{w}_{1}}} \mathrm{~L} \sin \phi \\
& \text { IV. Results }
\end{aligned}
$$

The effects of frequency of oscillation and material properties on the thermal and ablative oscillations can now be discussed in the light of the above solution. These effects are manifested in the amplitude of the thermal and ablative oscillations, the lag of these oscillations relative to those of the heat input, and crossovers of the ablative lag from a dynamically stabilizing to a destabilizing condition with changing frequency. The latter effect, an important dynamic stability consideration, is readily understood by examining ablative lags of $2 \pi-\epsilon$ and $2 \pi+\epsilon$ or $0-\epsilon$ and $0+\epsilon$, where $\epsilon<<\pi$. Assuming the ablative surface rearward of the plate center of gravity, the ablative momentum flux for the lag $2 \pi+\epsilon$ or $0+\epsilon$ assists the plate inertial force, a dynamically destabilizing condition. The flux for the lag $2 \pi-\epsilon$ or $0-\epsilon$ (actually an ablative lead) opposes the plate inertial force, a dynamically stabilizing condition.

The effects of frequency of oscillation on the thermal and ablative lag for no mass blockage are 
noted in Fig 2 and 3 for Teflon and quartz, respectively (material properties used in these calculations are listed in Table 1). Both the thermal and ablative lags approach zero for low frequency as expected. As frequency increases, the thermal lag rises rapidly, crosses $2 \pi$, and asymptotically approaches $9 \pi / 4$ as $\omega-\infty$. The ablative lag rises slightly, decreases, crosses $2 \pi$, and asymptotically approaches $2 \pi$ as $\omega \rightarrow \infty$. The asymptotic behavior as $\sqrt{2 \omega k} / v_{1}-\infty(\omega \rightarrow \infty)$ is the case of no ablation or ablation velocity negligible compared to the velocity $\sqrt{2 \omega \kappa}$. This result, as expected, is the same as that for no ablation as derived by Carslaw and Jaeger. $(5)$

The effect of frequency of oscillation on the nondimensionalized thermal and ablative oscillationamplitudes are indicated in Fig 4 and 5 . The amplitude and lag of the ther mal and ablative oscillations relative to the forcing heat input oscillation are indicated for frequencies $\omega=10^{-1}$ and $10^{3}$ radians per second in Fig 6 and 7 .

Although quartz is not a pure vaporizer and thus does not satisfy the problem conditions, it does illustrate the effect of material properties. The effect of material is on the ablative lag which is considerably higher for the Teflon material.

Mass blockage appears to cause little change in either the maxima of the ablative lag and lead or the crossover frequency as indicated in Table 2.

\section{Conclusions}

An analytic solution has been obtained for the thermal and ablative lag resulting from a periodic heat input to an ablating flat plate. The importance of this solutionlies in the revelation of a crossover from a dynamically stabilizing to a destabilizing condition (or vice versa) as the frequency of oscillation increases.

\section{References}

1. M. J. Lighthill and J. T. Stuart, Laminar Boundary Layer, L. Rosenhead, ed., Oxford University Press, New York, 1963.

2. N. Rott, "Time Dependent Laminar Boundary Layer," in Theory of Laminar Flows, F. K. Moore, ed., Princeton University Press, 1964.

3. H. A. Bethe and M. C. Adams, "Theory for the Ablation of Glassy Materials," J. Aero/Space Sci. (June 1959) 26:321-350.

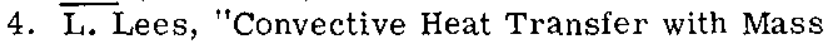
Addition and Chemical Reactions," Combustion and Propulsion, Third AGARD Colloquim, March 17-28, 1958, Palermo, Sicily, published by Pergamon Press, New York.

5. H. S. Carslaw and J. C. Jaeger, Conduction of Heat in Solids, 2nd ed., Clarendon Press, Oxford, 1959 .

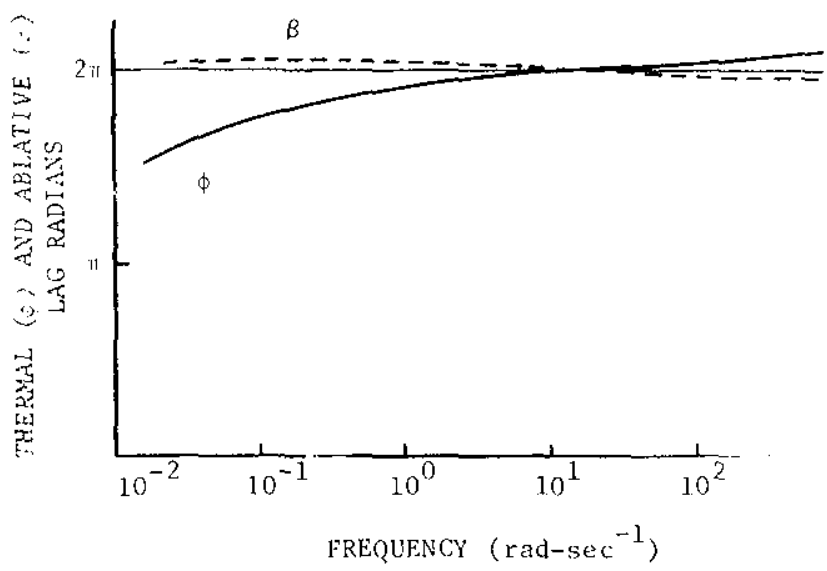

Figure 2. Thermal and Ablative Lag as a Function of Frequency for an Oscillating Flat Teflon PlateNo Mass Blockage

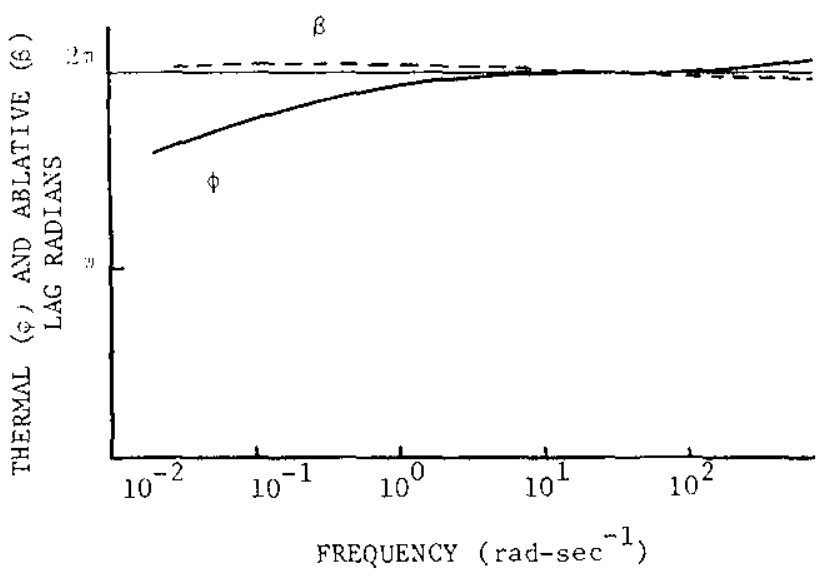

Figure 3. Thermal and Ablative Lag as a Function of Frequency for an Oscillating Flat Plate of Quartz - No Mass Blockage 


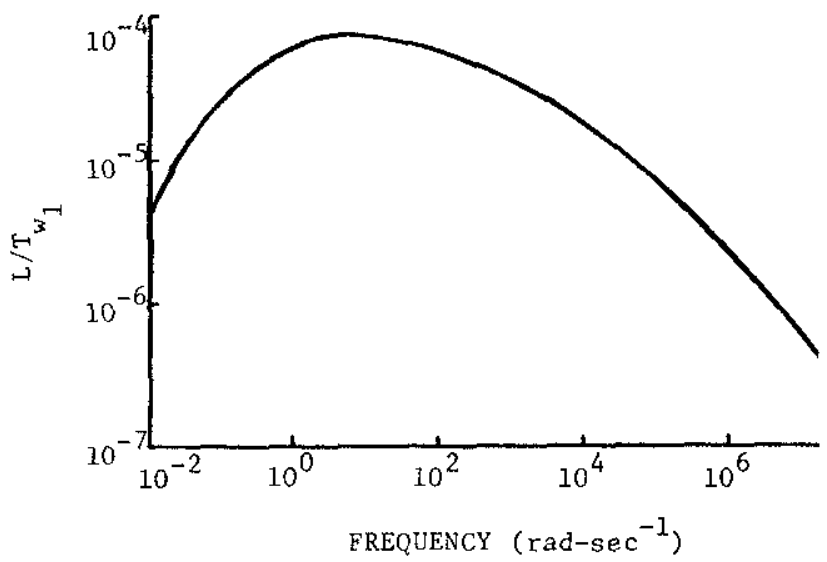

Figure 4. Relative Amplitude of Thermal Perturbation as a Function of Frequency - Teflon with No Mass Blockage

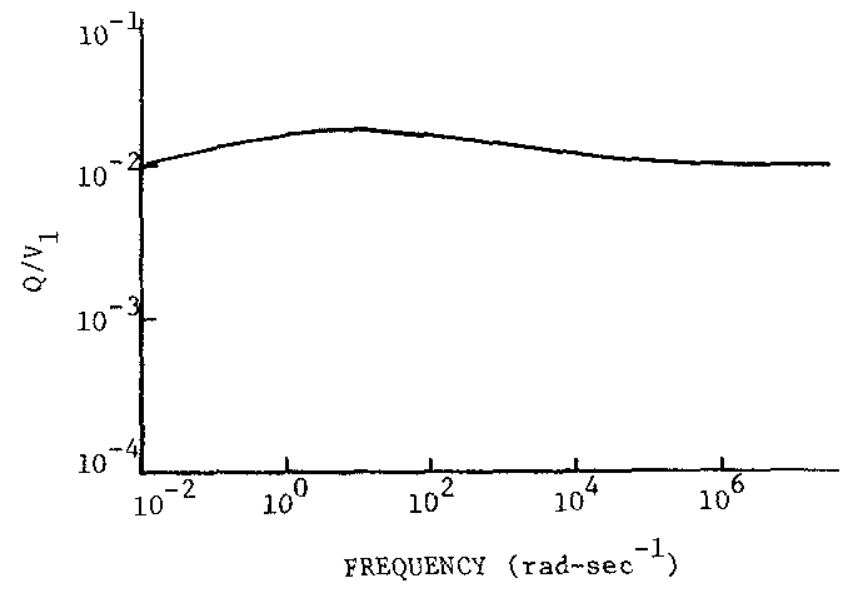

Figure 5. Relative Amplitude of Ablative Perturbation as a Function of Frequency - Teflon with No Mass Blockage

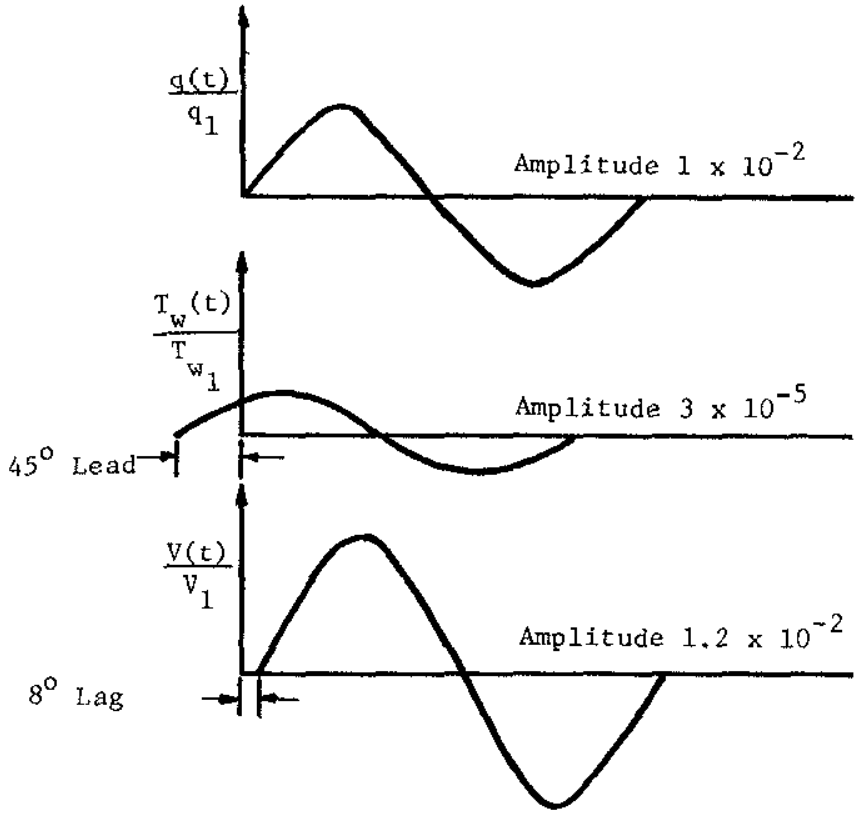

Figure 6. Pictorial Representations of Amplitude and Lag of the Thermal and Ablative Oscillations Relative to the Forcing Heat Input Oscillation at $\omega=10^{-1}$ Radians per Second

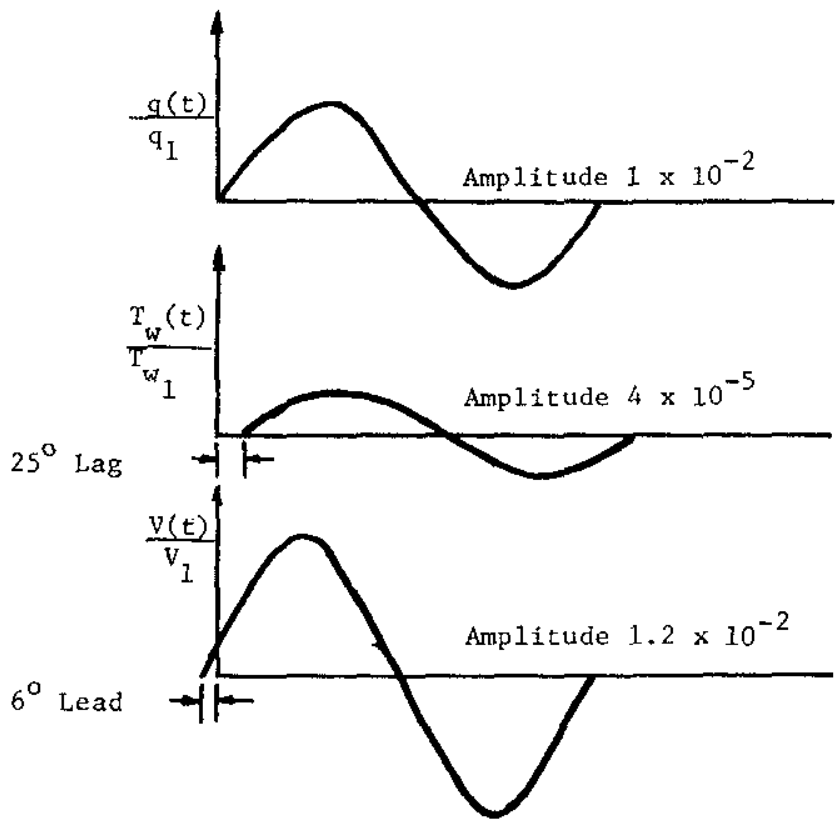

Figure 7. Pictorial Representation of Amplitude and Lag of the Thermal and Ablative Oscillations Relative to the Forcing Heat Input Oscillation at $\omega=10^{3}$ Radians per Second 


\begin{tabular}{|c|c|c|c|}
\hline Property & Units & $\underline{\text { Teflon }}$ & $\underline{\text { Quartz }}$ \\
\hline $\mathrm{T}_{\mathrm{w}_{1}}=$ steady-state wall temperature & ${ }^{\circ} \mathrm{R}$ & 1648 & 5803 \\
\hline$B_{1}=$ vapor pressure constant & & 23.87 & 27.615 \\
\hline $\mathrm{B}_{2}=$ vapor pressure constant & ${ }^{o} \mathrm{R}$ & 1580.0 & 5688.0 \\
\hline$q^{\prime}=$ heat transfer rate perturbation & $\mathrm{Btu} \cdot \mathrm{ft}^{-2} \cdot \mathrm{sec}^{-1}$ & 27.0 & 8.0 \\
\hline$q_{1}=$ steady-state heat transfer rate & $\mathrm{Btu} \cdot \mathrm{ft}^{-2} \cdot \mathrm{sec}^{-1}$ & 2700.0 & 800.0 \\
\hline$v_{1}=$ steady-state ablation velocity & $\mathrm{ft} \cdot \sec ^{-1}$ & $1.6 \times 10^{-2}$ & $8.22 \times 10^{-4}$ \\
\hline$\kappa=$ thermal diffusivity & $\mathrm{ft}^{2} \cdot \mathrm{sec}^{-1}$ & $3.41 \times 10^{-3}$ & $9.35 \times 10^{-6}$ \\
\hline $\mathrm{h}_{\mathrm{v}}=$ heat of vaporization & $\mathrm{Btu} \cdot 1 \mathrm{bm}{ }^{-1}$ & 750.0 & 5500.0 \\
\hline$c_{p}=$ specific heat & $\mathrm{Btu} \cdot \mathrm{lbm}^{-1} \cdot a_{\mathrm{R}}{ }^{-1}$ & 0.30 & 0.25 \\
\hline $\begin{aligned} & \Delta h= \text { enthalpy difference across } \\
& \text { boundary layer }\end{aligned}$ & $B t u \cdot l b m^{-1}$ & 8470.0 & 7453.0 \\
\hline $\mathrm{p}=$ local pressure & atm & 3.963 & 3.963 \\
\hline $\mathrm{p}_{\mathrm{v}_{1}}=$ steady-state vapor pressure & atm & 2.65 & 1.72 \\
\hline$\rho=$ material density & $\mathrm{lbm} \cdot \mathrm{ft}^{-3}$ & 137.0 & 140.0 \\
\hline $\begin{aligned} \mathrm{M}= & \text { molecular weight ratio } \\
& \text { (air to material vapor) }\end{aligned}$ & & 0.29 & 0.72 \\
\hline
\end{tabular}

Table 1. Material Properties and Environmental Conditions for Teflon and Quartz

\begin{tabular}{|c|c|c|}
\hline & $\begin{array}{c}\text { Mass } \\
\text { Blockage }\end{array}$ & $\begin{array}{l}\text { No Mass } \\
\text { Blockage }\end{array}$ \\
\hline Crossover frequency $\left(\mathrm{rad} \cdot \mathrm{sec}^{-1}\right)$ & $\sim 15$ & $\sim 15$ \\
\hline Maximum ablative lag (rad) & 0.140 & 0.139 \\
\hline Maximum ablative lead (rad) & 0.103 & 0.101 \\
\hline
\end{tabular}

Table 2. Effects of Mass Blockage on the Ablative Lag

Appendix I

The constants $C_{1}, M, N, S$ are defined

$$
\begin{aligned}
C_{1}= & \frac{-A B-A D F H+B D\left(1+H^{2}\right)+D G H F-B G H^{2}+A F G H-F G^{2} H+A E F-F E G}{A^{2}+D^{2}\left(1+H^{2}\right)+G^{2} H^{2}-2 A D-2 D G H^{2}+E^{2}\left(1+H^{2}\right)-2 A E H+2 E G H} \\
& +\frac{i\left[-A^{2} F+A B H+A E F H-E B\left(1+H^{2}\right)-E G H F+A G F-B G H+A D F-F D G\right]}{A^{2}+D^{2}\left(1+H^{2}\right)+G^{2} H^{2}-2 A D-2 D G H^{2}+E^{2}\left(1+H^{2}\right)-2 A E H+2 E G H} \\
W= & -A B-A D F H+B D\left(1+H^{2}\right)+D G H F-B G H^{2}+A F G H-F G{ }^{2} H+A E F-F E G \\
N= & -A^{2} F+A B H+A E F H-E B\left(1+H^{2}\right)-E G H F+A G F-B G H+A D F-F D G \\
S= & A^{2}+D^{2}\left(1+H^{2}\right)+G^{2} H^{2}-2 A D-2 D G H^{2}+E^{2}\left(1+H^{2}\right)-2 A E H+2 E G H
\end{aligned}
$$

